Article

\title{
Numerical Modeling Rolling Contact Problem and Elasticity Deformation of Rolling Die under Hot Milling
}

\author{
Mesay Alemu Tolcha ${ }^{1, t, \ddagger(1)}$ and Prof. Holm Altenbach ${ }^{2, \ddagger}$ \\ 1 Jimma institute of Technology, Jimma University Jimma, Ethiopia; \\ alemu170@yahoo.com/messay.alemu@ju.edu.et \\ 2 Fakultt für Maschinenbau, Otto-von-Guericke-Universität Magdeburg; holm.altenbach@ovgu.de \\ * Correspondence:alemu170@yahoo.com/mesay.tolcha@ovgu.de ; Tel.: +491577458691 \\ † Current address: Fakultt für Maschinenbau, Otto-von-Guericke-Universität Magdeburg; \\ mesay.tolcha@ovgu.de \\ $\ddagger \quad$ These authors contributed equally to this work.
}

\begin{abstract}
In the world industry plant, solid and solid metals are always in contact even their motions not independent. Modeling of rolling die contact with slab primarily needs to describe the Tribology of contact phenomena. Consideration of continuum theory of rolling contact how a contact region is formed between rolling die and slab, and how the tangential force is distributed over the contact area with coefficient of friction is important. The central concern of numerical model is used in this work to indicate a set of equations, derived from the contact principle, that transfer the physical event into the mathematical equations including the laws of nature, such as newton's laws, boundary conditions, state of stresses and their derivatives at particular time and locations. In this paper the elasticity stress behavior of rolling die contact with slab for number of cyclic loads is modeled. The model is including new proposed constitutive equations for discontinuity of the velocity, pressure distribution in rolling contact from the enter side to exit side of the neutral point. To verify the model, finite element simulation and experimental data from the literature are considered. The results show good agreement with finite element simulation and experimental data.
\end{abstract}

Keywords: Continuum Rolling Contact; Geometry Relationship; Pressure Distribution; Stress Behavior; Rolling Die and Slab

\section{Introduction}

The manufacturing process is the application of engineering industries. It shows how the different problems related to various machine components that may be solved by a study of physical or other governing laws. Continuous casting process is one of the leading industries in the metal manufacturing process. In continuous casting process hot metal stock passed between two rolling dies with plasticity deformation properties when a compressive force is applied from the set of two dies. The two dies have equal size and rotate in the opposite direction with the same rotational speed. The space between two rolling gap is less than the thickness of the entering slab, as shown in the Figure 1. As a consequence, die contact with the slab must be slid in the normal application. Since the friction and plasticity deformation are the results of an interactions between contacting bodies at their interface, the nature of contact cannot be understood without explaining the nature of interface information. Modeling of the contact information is one the subject of Tribology which is a branch of quasi-static phenomena. 


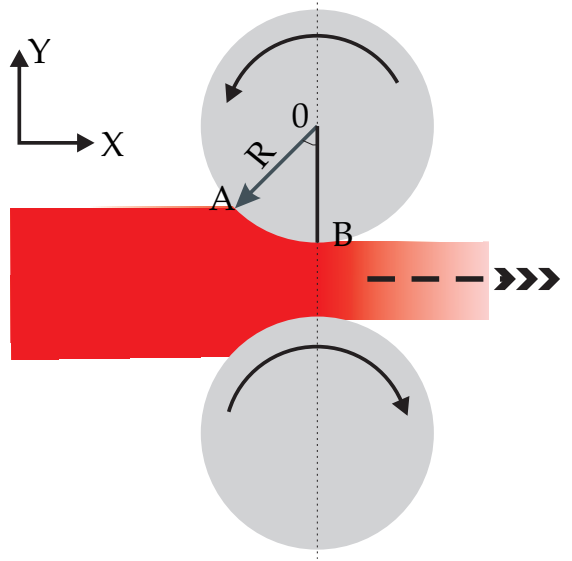

Figure 1. Geometrical relation between rolling die and flat rolling

Rolling process is a contact between the work piece and rolling die. Three main points of views are usually considered in rolling contact, i.e. mechanical, macroscopic and microscopic point of view [1]. To understand rolling contact from the beginning the these point of views are considered mainly from a mechanical point of view through summarizing the previous works. E.g., wheel railway and automotive tire behavior, energy losses in bearings, distortion in a printing press image,profile development and hertz contact theory. In short, Metal forming contact problems will not fall into the preceding categories (Hertzian elastic or frictionless cones/punches) and require their own modeling. The common problems of this sort are complex geometry and nonlinearity of elasticity and plasticity properties. So, there is no clear situation for explanation. At any time continuum rolling contact theory must be invoked based on the nature of contact area and application.

Solid understanding of the behaviour of rolling contact is necessary for successful contact modeling. Whether the model is predictive or adaptive phenomena in the roll gap to describe the contact area needs clear information. When the two surfaces approach one-another, contact occurs only at discrete points, the total area of which is defined as the true area in the contact. The magnitude and deformation under normal and shear loading are key pieces of information needed to interpret and understand the Tribology mechanisms. One of the first attempts in analyzing the development of the true area of contact, using slip line field analysis the deforming work piece, was presented by [2]. The actions of the asperities in contact and the development of models for friction in metal working were studied by [3]. According to the model the growth of the real contact area is faster at high shear stresses and approaches the apparent one at high pressures. The results were approximated using exponential functions to analyze metal forming problems, but these things, not enough for clear justification. So, detail analyzing is necessary.

\section{Rolling Contact Problem}

The contact problem with rolling die is the most challenge issues in metal-forming process due to intrinsically difficult of mathematical problem corresponding to the discontinuity of the velocity. If the contact information is not taken into account properly, the final results of the computation are greatly affected and can be wrong. This topic is not straightforward from an engineering point of view. So, it needs a systematic approach with theoretical background in the field of functionality analysis. Most studies on continuum rolling contact are interested on how the physical phenomena proceeds and may neglect the gradual inertia effects. There are certain studies in $2 \mathrm{D}$ and $3 \mathrm{D}$ dimensional contact elastic and plastic dynamics analyzed in the work [4-8].

To start the analysis, let's suppose that the surface of the die is described by function $g$ with coordinate $x$ 
- $g(x)=0$ is the surface of the die

- $g(x)<0$ is the interior of the die. It is valid for any in the interior of the die.

The outer normal die is defined by

$$
n=\frac{1}{|\partial g(x) / \partial x|} \frac{\partial}{\partial x}
$$

To prove the above assumption through the mathematical application, let's further consider that two bodies are under the motion. Incremental of the time $t$, expressed by the terms of velocity. When finite time intervals are considered, approximation displacement can be made through consideration velocity formulation. In the same way, assume that the die is in the contact with slab for which the domain $Q$ can be represented by a function $g(, x)$, i.e. as a function of the coordinate $x$ and $t$ as:

$$
g(x, t)=0
$$

At time $t$ slab point coordinate $x^{\prime}(t)$ is on the die surface if

$$
\left.g\left[x^{\prime}(t), t\right)\right]=0
$$

And at the time $t+d t$ the same slab point on the die surface has moved such that the new coordinate vector $x^{\prime}(t+d t)$ will satisfy

$$
g[x(t+d t), t+d t]=0
$$

which is transformed with a first-order taylor expansion and gives

$$
g\left[x^{\prime}(t+d t), t+d t\right] \cong g\left[x^{\prime}(t), t\right]+\frac{\partial g}{\partial x}\left[x^{\prime}(t), t\right] \frac{d x^{\prime}}{d t}+\frac{\partial g}{\partial t}\left[x^{\prime}(t), t\right] d t=0
$$

in short, Eq.(5), can be replaced by

$$
x^{t+\Delta t}=x^{t}+\Delta t V^{t+\Delta t}
$$

This allows us to update the domain $Q$ into $x^{\prime}(t+d t)$ and to continue the calculation. Due to its simplicity, this scheme obviously helps in better understanding as shown in the Figure 2 . They have the same location at time $t$, that is $x(t)=x^{\prime}(t)$, then, one can get

$$
\Delta V=V_{s}-V_{r}
$$

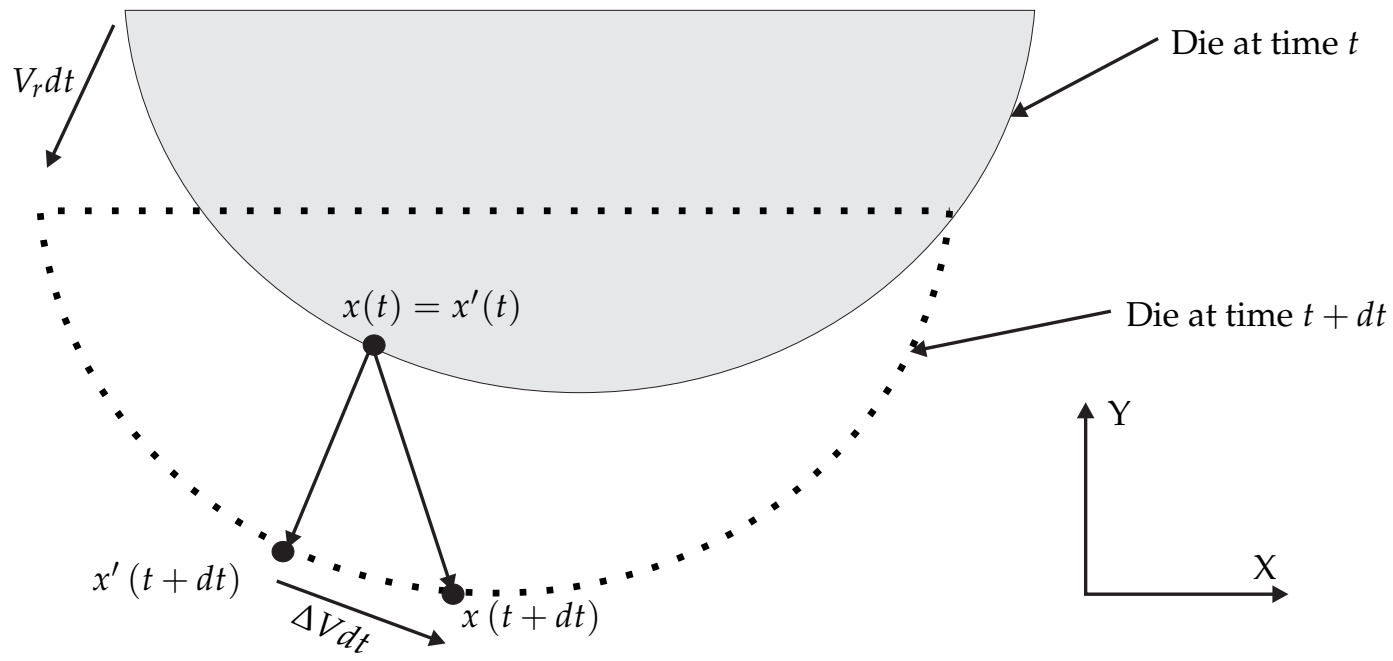

Figure 2. Analysis the contact information

For general curved surface, approximated finite incremental times are considered, but Eq.(7) is not enough to explain all possibilities of physical situations that can occur in the realities. Because it 
couldn't allow the slab points to penetrate in the die or loss of contact. Figure 3 shows slab gliding on the rolling die with mathematical is expressed. The summary of this justification expressed with mathematical equation as follows:

$$
\text { if } \quad \sigma_{n}=(\sigma \cdot n) \cdot n<0 \quad \text { then, } \Delta V \cdot n=0
$$

This means the slab point is already on the contact surface at the beginning of the increment. Then the slab point must remain in contact with the die, and due to the curvature of the die at the end of increment the point exhibits a small departure from the die surface but it must be reprojected

$$
\text { if } \quad \sigma_{n}=(\sigma \cdot n) \cdot n=0 \quad \text { then, } \Delta V \cdot n \geq 0
$$

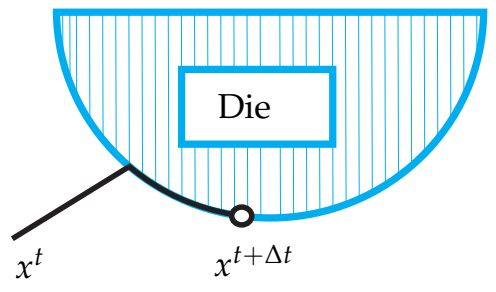

a)

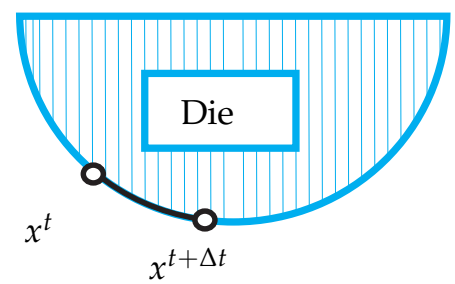

b)

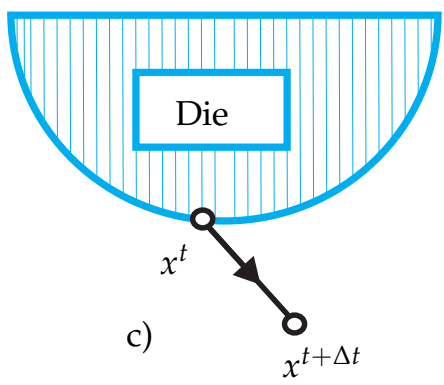

c)

Figure 3. Incremental contact the rolling die is assumed that fixed. a) contact establishment, b) gliding contact, and c) loss of contact

The slab point is on the free surface at the beginning of the increment, and penetrates inside the die at the end of the increment. It is possible reproject orthogonally the point with coordinates $x^{t+\Delta t}$ on the surface of the die through reducing the time increment such that it is possible to choose the minimum time $t^{*}$ for all the points coming into contact. There is an accurate technique for further analysis, which may increase the number of time increments significantly, mainly in three-dimensional analysis. Let's further summarize this presentation using the three main incremental point contacts with the level of implicitly schemes

1. The slab point and die are free surfaces at the beginning of the increment and come into contact during the increment

2. Both bodies are already in the contact at the beginning of the increment and the normal compressive stress both at the beginning and at end of the increment remain in contact.

3. The slab point is in contact at the start of the increment, but the normal stress becomes zero, then the slab is allowed to leave the die surface.

\section{Tribology of Metal Rolling and Geometry Relationship}

The phenomena of contact between rolling dies and slab, can best explained in terms of the friction hypothesis which examines the origin of the resistance to relative motion in terms of slid or stick between the two contacting surfaces. The hypothesis, presented by [9], which is credited to the French scientist Desaguliers, explains, the origin of resistance to motion in terms of adhesive bonds. The hypothesis stated that engineering to surfaces are never completely smooth, and they contain asperities and valleys, when viewed under suitable magnification. In metal rolling, friction is responsible to draw the metal into the dies.

Friction is a phenomenon when shearing stress acts tangential to the dies at any section along the arc of contact between dies and slab. However, the direction of shearing reverses at the neutral point $[10,11]$. Between the entry section of the roll gap and the neutral section, the direction of friction is the same as the direction of motion of the slab into the roll gap. Therefore, the friction aids 
in pulling the slab into the rolls in this part of the travel. The direction of friction reverses after the neutral point, as the velocity of the slab is higher than the velocity of the rolls (see Figure 4).

Friction force opposes the forward motion of the slab in beyond the neutral section, in the same way, rolling die pull into forward. The magnitude of the friction acting ahead of neutral section is greater than that beyond the neutral section. Therefore, the net friction is acting along the direction of the slab movement, thereby aiding the pulling of the slab into the roll gap.

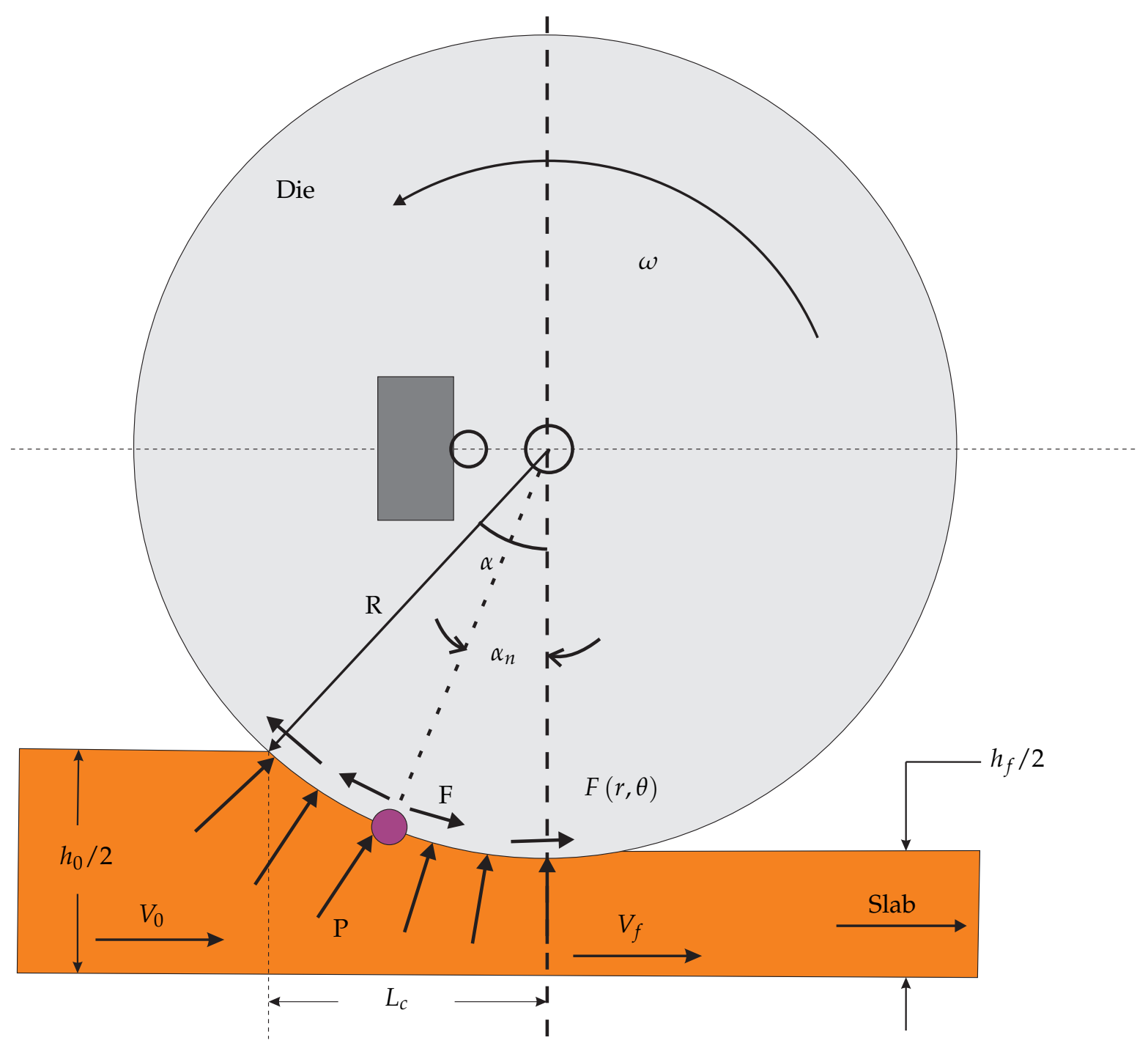

Figure 4. Action of friction and normal force in the contact area

Rolling die exert a normal pressure $P$ on the slab. This pressure may be imagined to be the pressure exerted by the slab on the dies to separate them. Due to the friction force in the tangential direction, $F$, frictional shear stress is induced at the interface between die and slab. The derivation of the equation is illustrated in Figure 5

$$
F=\mu P
$$

where $\mu$ is coefficient of friction and $\mathrm{P}$ is rolling pressure. Based on the variations in application conditions, the slip coefficient friction is considered between the rolling die and slab. At the entry section, i.e. if the forces acting on the slab are balanced, Eq.(10) can be formulated as:

$$
P \sin \alpha=\mu P
$$



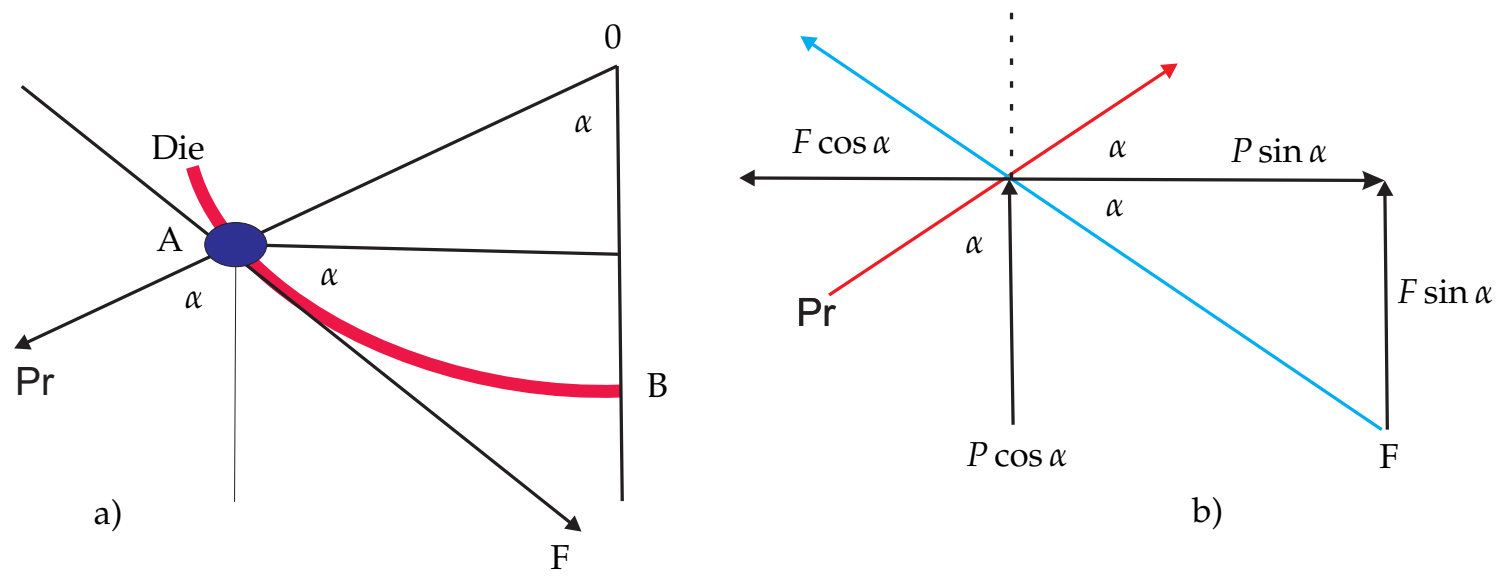

b)

Figure 5. Component force. a) Direction of the two forces, b) Resolved force that act on rolling die

The area over which both forces are acting is the same. The slab is to be pulled into the rolls at entry section without considering the slab bulging out in the transversal direction, even such problem may happen in continuous casting at an early stand of deformation. The following condition is to be satisfied

$$
\begin{gathered}
\mu P \cos \alpha \geq P \sin \alpha \\
\mu \geq \tan \alpha
\end{gathered}
$$

These problem are stated with the general mathematical terms. Now let's proceed for detail mathematical expression with necessary condition. E.g, angle of bite or angle of contact, Slip direction in arc contact and neutral point, as shown in Figure 4. Before going to determine the relationship between force and geometry in rolling contact first have to consider the plastic deformation of the slab direction. As per theory of metal rolling width incremental result is zero. So, the vertical compression of the metal is translated into an elongation in the rolling direction. As the slab is dragged by the rolls into the roll gap, it decreases in thickness while passing from the entrance to the exit. From the volume metal conservation law, one can write the following equation

$$
w h_{0} V_{0}=w h V=w h_{f} V_{f}
$$

where $w$ is width of deformed slab, $V$ is velocity at any thickness and $h$ is intermediate between $h_{o}$ and $h_{f}$ thickness. At the mean time slab velocity gradually increases from $V_{0}$ at the entrance to $V_{f}$ at the exit. In order that vertical elements in the metal remain undistorted, Eq.(14) requires that the exit velocity $V_{f}$ must be greater than the entrance velocity $V_{0}$. Due to the variation in the velocities of die surface and slab surface there will be relative motion between them. The relative motion between the die and the slab is referred as a slip. Slip takes place at the front and the back of the rolling dies. There is a point where the velocity of the metal the surface velocity of the die $V_{r}$ equal to the velocity of slab $V_{s}$ this point called neutral point. It is indicated in Figure 4 by angle $\alpha_{n}$. Before determining the neutral point, let's find angle of contact. The angle $\alpha$ between the entrance plane and the centerline of the rolling die is shown in Figure 6. From the definition of circular segment and using Taylor's series expansion, $\alpha$ can be find as follows

$$
\begin{gathered}
h=h_{f}+2 R(1-\cos \alpha) \\
\cos \alpha=1-\frac{\alpha^{2}}{2 !}+\frac{\alpha^{4}}{4 !} \ldots \\
h=h_{f}+R\left(\alpha^{2}\right)
\end{gathered}
$$




$$
\cos \alpha=1-\frac{\Delta h}{2 R}
$$

where, $\Delta h=h_{0}-h_{f}$.

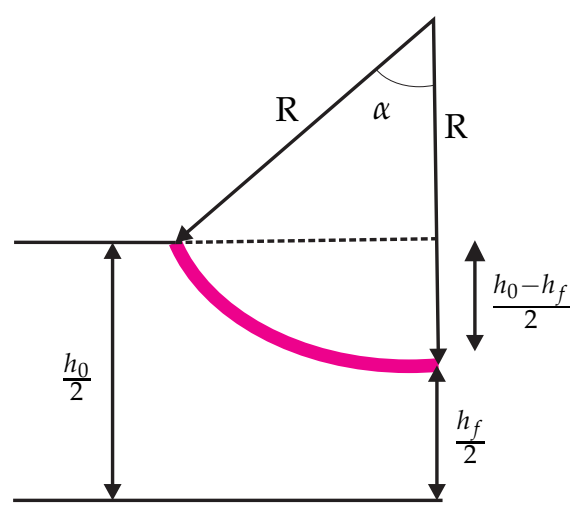

Figure 6. Analysis of angle contact bite

The position of the neutral angle (the pseudo independent parameter) also determined as one of independent function parameters from Eq.(4) and rearranging the equation developed in [12] and considering hot rolling condition as well as other analyses based on [13]. The rest analytical treatment is presentation of section with symmetry assumption. Top and bottom are mirrored around the plane of symmetry. So, the pressure distribution and the position of the neutral point are identical for the top and bottom or left and right side. Taking the above justification into account the location of the neutral point is calculated by

$$
\alpha_{n}=\sqrt{\frac{h_{f}}{R}} \tan \left(\frac{H_{n}}{2} \sqrt{\frac{h_{f}}{R}}\right)
$$

where, $H_{n}=\sqrt{\frac{h_{f}}{R}}-\frac{1}{2 \mu} \ln \sqrt{\frac{h_{f}}{R}}$

$$
\alpha_{n}^{\prime}=\sqrt{\frac{h_{f}}{R^{\prime}}} \tan \left(\frac{H_{n}}{2} \sqrt{\frac{h_{f}}{R^{\prime}}}\right)
$$

where rolling die flattening $\mathrm{R}^{\prime}$ determined from Hitchcock's equation [14]

$$
R^{\prime}=R\left[1+\frac{c P^{\prime}}{w\left(h_{0}-h_{f}\right)}\right]
$$

where, $c=16\left(1-v^{2}\right) / \pi E_{r}, P^{\prime}$ is roll pressure with flattened die and $E_{r}$ is young's modulus of the die material.

\section{Pressure Distribution in Contact Area}

The shape of the die-slab contact surface is not known at exact point. The computation of the roll pressure distribution must be combined with the deformed slab contour and dies iterative technique by suitable equation. A number of theories and equations were attempted in this area earlier, but there are no rationalized differences between them or no one has got popularity over the others. E.g., bland and ford's model (1948), sims' model (1954), alexander's model (1972), refinement of the orowan models (1984 and 1991) and new cold-rolling theory (2009)

Varying theories are reviewed in this section from the beginning up to the recent research done in $[15,16]$, in terms of the assumptions and simplifications made either during their development and 
derivation, or when roll pressures and forces are calculated. But they have no consideration of hot working conditions. It is amazing, no model has been found which is repeatable, and gives better predictions than the others. However most of the approaches offered some unique advantage and also had deficiencies of one sort or another. We think that the choice of those models based on the knowledge of researchers and professionals on the specific domain.

Hot-rolling has no advance to the state of knowledge that exists for cold-rolling due to the problem of inhomogeneous deformation and less well defined friction conditions. In hot-working condition the flow stress is also a function of temperature and speed of rolling die. With the above-mentioned plasticity/elastic deformations and other relative issues after considered, pressure distribution equation between rolling die and slab is proposed. For this approach the following assumption are considered, that is the same state of stress exists at all points of the plane $x, y$ and $z$ directions. In the same way, considering a volume element of unit width having the instantaneous thickness change $d h$ and length $d x$ (see Figure 7). Assume, furthermore, that the longitudinal stress $\sigma_{x}$, constant over a plane normal to the $x$ direction, and the pressure $\sigma_{y}=-P$ acting on rolling die interface, are the two principal stresses which are acting. Result of assuming that a slab is deformed in the plane.

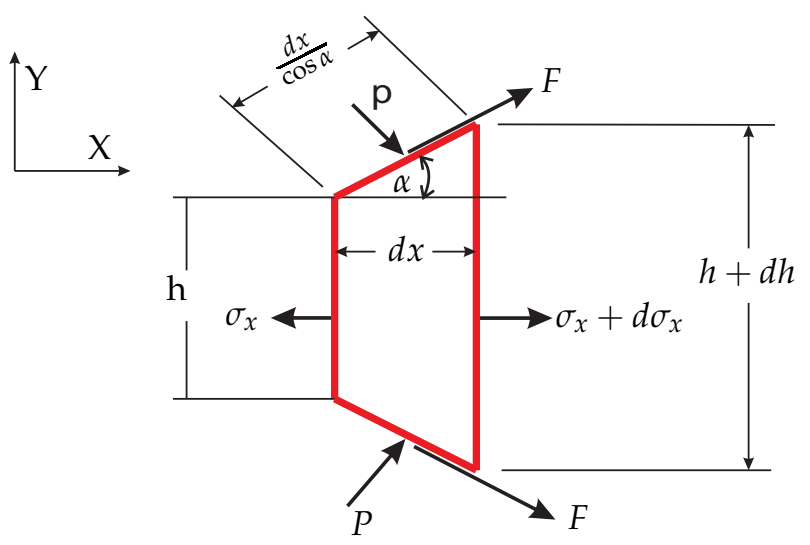

Figure 7. Stresses on slab element

Taking the equilibrium of forces in the vertical direction results in a relationship between the normal pressure and the radial pressure. The relationship between the normal pressure and the horizontal compressive stress $\sigma_{x}$ is given by the distortion energy criterion of yielding for plane strain. Because of symmetry, the metal flows away from the centre plane in both directions, and it will be sufficient to analyze the conditions for half side. By introducing the shearing stresses, $F=\tau_{x y}$ acting on the surface, the equilibrium of the $x$ component of the forces acting on a volume element is expressed by

$$
h d \sigma_{x}+\sigma_{x} d h+2 P d a x(\tan \alpha+\mu)=0
$$

Distortion-energy condition for plane

$$
\sigma_{x}-\sigma_{y}=\frac{2}{\sqrt{3}} \sigma_{y 0}=\frac{2}{\sqrt{3}} \sigma_{0}=\sigma_{0}^{\prime}, \quad \sigma_{x}=\sigma_{0}^{\prime}-P, \quad d \sigma_{x}=-d P
$$

Substitute Eq.20 into the Eq.(19)

$$
-h d P+\left(\sigma_{0}^{\prime}-P\right) d h+2 P d x(\tan \alpha+\mu)=0
$$

By considering that

$$
d x=\frac{d h}{2 \tan \alpha}
$$


Then, one can get

$$
h d P-\left(\frac{\mu P}{\tan \alpha}+\sigma_{0}^{\prime}\right) d h=0
$$

let's introduce the parameter $\mathrm{w}^{\prime}$, that is defined by the equation

$$
\tan w^{\prime}=\sqrt{\frac{R}{h_{f}}} \tan \alpha
$$

Follow the producer of Eq.(15)

$$
h=h_{f}\left(1+\tan w^{\prime}\right)
$$

Its derivative with respect to the parameter $\mathrm{w}^{\prime}$ is

$$
\frac{d h}{d w^{\prime}}=2 h_{f} \tan w^{\prime}\left(1+\tan w^{\prime}\right)
$$

Substituting the expressions from Eq.(25) and (26) into Eq.(23) and introducing the the constant

$$
\phi=2 \mu \sqrt{\frac{R}{h_{f}}}
$$

One has differential equation and multiplying both sides by $e^{\phi w^{\prime}}$

$$
e^{\phi w^{\prime}}\left(d P-\left(P \phi+2 \sigma_{0}^{\prime} \tan w^{\prime}\right) d w^{\prime}\right)=0
$$

At the end, rearranging and then integrating:

$$
P=e^{\phi w^{\prime}}\left(2 \sigma_{0}^{\prime} \int e^{-\phi w^{\prime}} \tan w^{\prime} d w^{\prime}+C_{1}\right)
$$

where $C_{1}$ is constant of integration. According to Rodney [17], the integral appearing in this equation can be calculated with sufficient approximation by putting $\tan w^{\prime} \approx w^{\prime}$, then

$$
\int e^{-\phi w^{\prime}} \tan w^{\prime} d w^{\prime}=-\frac{e^{-\phi w^{\prime}}\left(1+\phi w^{\prime}\right)}{\phi^{2}}
$$

The general solution of this equation

$$
\frac{P}{\sigma_{0}^{\prime}}=C e^{-\phi w^{\prime}}-\frac{2}{\phi^{2}}\left(1-\phi w^{\prime}\right)
$$

From above expression

$$
\frac{\sigma_{x}}{\sigma_{0}^{\prime}}=1-\frac{P}{\sigma_{0}^{\prime}}=1-C e^{-\phi w^{\prime}}-\frac{2}{\phi^{2}}\left(1-\phi w^{\prime}\right)
$$

At the boundary condition of enter side (just at outside of enter point), $\left(\sigma_{x}\right)_{x=0}=0$, and $C$ can be obtained from Eq.(32) with this condition. And then, furnish the above expression with all situations, the pressure distribution on the entrance side of the neutral point can be given as

$$
\frac{P}{(2 / \sqrt{3}) \sigma_{0}}=e^{\phi\left(w_{0}^{\prime}-w^{\prime}\right)}+\frac{2}{\phi^{2}}\left(e^{\phi\left(w_{0}^{\prime}-w^{\prime}\right)}\left(1-\phi \cdot w_{0}^{\prime}\right)-\left(1-\phi \cdot w^{\prime}\right)\right)
$$


The pressure distribution on the exit side of the neutral point is expressed as:

$$
\frac{P}{(2 / \sqrt{3}) \sigma_{0}}=e^{\phi \cdot w^{\prime}}+\frac{2}{\phi^{2}}\left(e^{\phi \cdot w^{\prime}}-\left(1+\phi \cdot w^{\prime}\right)\right)
$$

where

$$
w^{\prime}=\tan ^{-1}\left[\sqrt{\frac{R}{h_{f}}} \tan \alpha_{n}\right], \quad w_{0}^{\prime}=\tan ^{-1}\left[\sqrt{\frac{R}{h_{f}}} \tan \alpha\right]
$$

and

$$
\begin{gathered}
\mu=1.05-0.0005 T-0.056 V_{r} \\
\mu=-1.607-0.13 V_{r}+1.256 \\
\mu=\frac{\Delta h / R^{\prime}}{2 \sqrt{\frac{\Delta h}{R^{\prime}}}-4 \sqrt{\frac{2 S_{f} h_{f}}{2 R^{\prime}-h_{f}}}}
\end{gathered}
$$

where $T$ is the temperature, given here in ${ }^{\circ} \mathrm{C}$ and $\mathrm{V}_{\mathrm{r}}$ is the rolling velocity in $\mathrm{m} / \mathrm{s}$. For steel rolls the relevant formula for $\mu$, Eq.(36) developed by Geleji and even quoted by different researchers. In the same way, Eq.(38) and (37) are suggested in [18] and [19], respectively. Where the $\mu$ dependence on the surface velocity of the rolling die, reduction and temperature is shown in Figure 9. The result shows that $\mu$ is decreases with increasing rolling die speed and temperature, in the same way, affected by reduction ratio.

In Figure 10 two lines are intersected at the neutral point due to the action of compression and tension force where the model is derived from Eq.(33) and (34). For this method, $R=100 \mathrm{~mm}$, $h_{\mathrm{f}}=40 \mathrm{~mm}, T=500^{\circ} \mathrm{C}$ and $V_{\mathrm{r}}=5 \mathrm{~m} / \mathrm{s}$ are considered, the result indicate that tension force greater than the compressive load, which means maximum stress exerted on the rolling die from exited side rather than the enter side of neutral point. In the same way, FORTRAN program was developed to simulate this phenomena in ABAQUS as shown in Figure 11. Where is the result shows maximum stress distribution of induced in rolling die at enter and exit side, respectively. On the other hand, finite element simulation agree with the numerical computation that implemented in python along the arc of contact when plasticity deformation is performed. However, the numerical model is show that exaggerated stress at the specific point which means maximum tension stress developed due to maximum velocity of slab from exit side is high. Finally, the result suggest that tension load exerted on rolling die is different from the enter side to exit side in magnitude and direction.

To get unified equation, let's find the mean rolling die pressure at interface through integration. Considering a volume element of unit width having the instantaneous thickness $h$ and length $d x$ (see Figure 8).

$$
h d \sigma_{x}-2 \tau_{x y} d x=0
$$

Which is obtained by substituting Eq.(20) in the Eq.(39), and then separating the variables. In addition, it is known that the relationship of Coulomb's law in slide friction is given by, $\tau_{x y}=\mu P$

$$
d P+2 \frac{\mu P}{h}=0, \quad \frac{d p}{p}=-2 \frac{\mu d x}{h}
$$

Integrating both sides

$$
\ln P=-\frac{2 \mu x}{h}+C \quad \text { or } \quad P=C_{1} e^{-2 \mu x / h}
$$


where $C_{1}=e^{c}$ is a new integration constant to be determined from the boundary condition at $x=L_{c} / 2$ where $\sigma_{x}=0$, and consequently $P=\sigma_{0}^{\prime}$ then obtain

$$
C_{1}=\sigma_{0}^{\prime} e^{\left(\mu L_{c} / h\right)}
$$

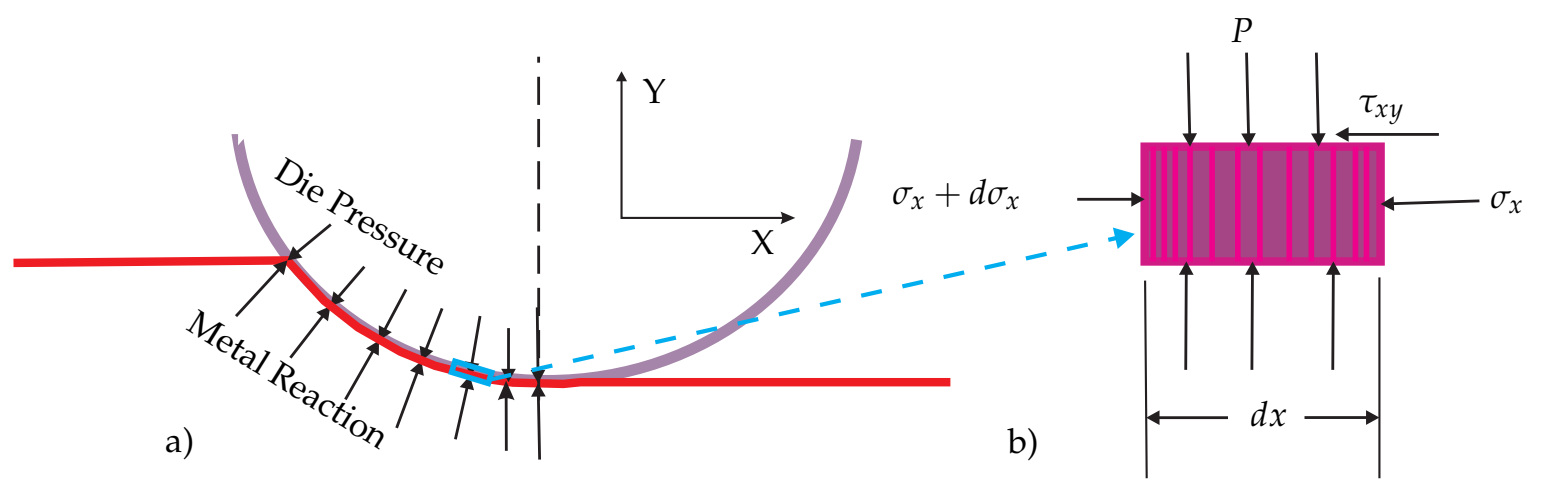

Figure 8. Load relationship under rolling contact. a) Load acting on slab/die, b) Dimension of a volume element of plate in rolling contact, and stresses acting on volume element

After substitution, the mean pressure is

$$
\tilde{P}=\int_{0}^{L_{c}} \frac{P d x}{L_{c}}=\sigma_{0}^{\prime} \frac{e^{\mu L_{c} / h}-1}{\mu L_{c} / h}
$$

where, $h=\left(h_{0}+h_{f}\right) / 2$ and $L_{c}$ is the length of contact between the slab and rolling die as shown in the Figure 4. In Figure 12 computational result of mean pressure is compared with the Eq.44 and (45), which is purposely developed for hot working condition by [20] and [21], respectively

$$
\begin{gathered}
P=\sigma_{0}^{\prime}\left(1.31+0.53 \frac{L_{c}}{\sqrt{h_{0} h_{f}}}\right) \\
P=\sigma_{0}^{\prime}\left(\frac{\pi}{2}+\frac{L_{c}}{h_{o}+h_{f}}\right)
\end{gathered}
$$

In Figure 12, where reduction ratio, and roll diameter are constant, the angle contact length is the relative distance along $x$. The same basic equation for hot-rolling with important condition that the equation which were given for determining the effective pressure in rolling gap. Upon comparison, the difference between the models were appeared as per the authors concern but for continuous casting the proposed model is fair enough because the main objective of continuous casting is supporting highly heated metal for further subsequent strands rather breakdown the casting ingot into slab/bloom under single strand. However, for given $\mathrm{L}_{\mathrm{c}} / \mathrm{h}$ increasing coefficient of friction easily heads to more than a doubling of the deformation pressure. The role of $\mu$ in raising pressure distribution should be clear from above calculation. Note also that the role of $\mu$ becomes particularly important at large values of $L_{c} / h$. 


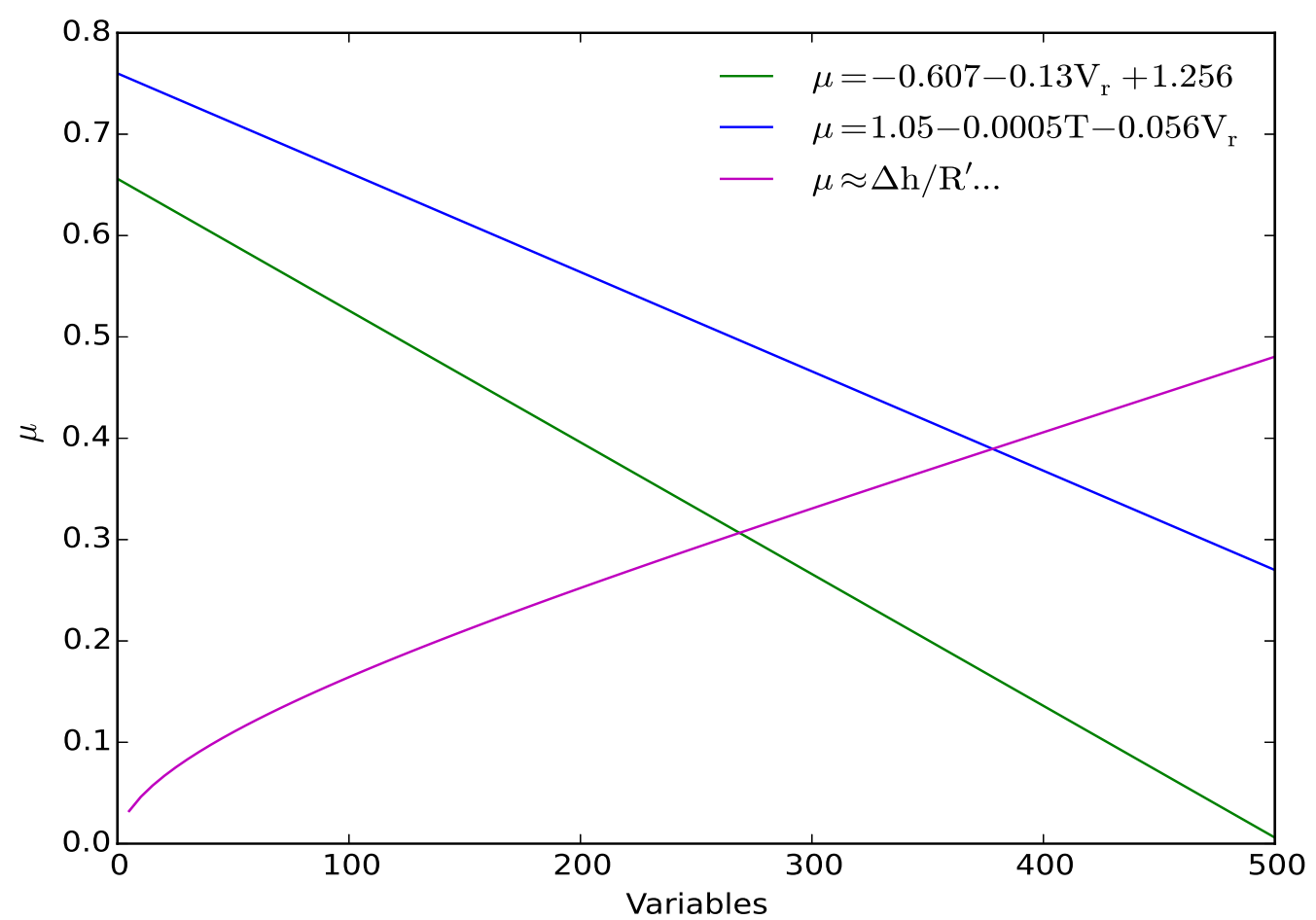

Figure 9. The coefficient of friction as a function of the temperature, reduction and the rolling die surface velocity

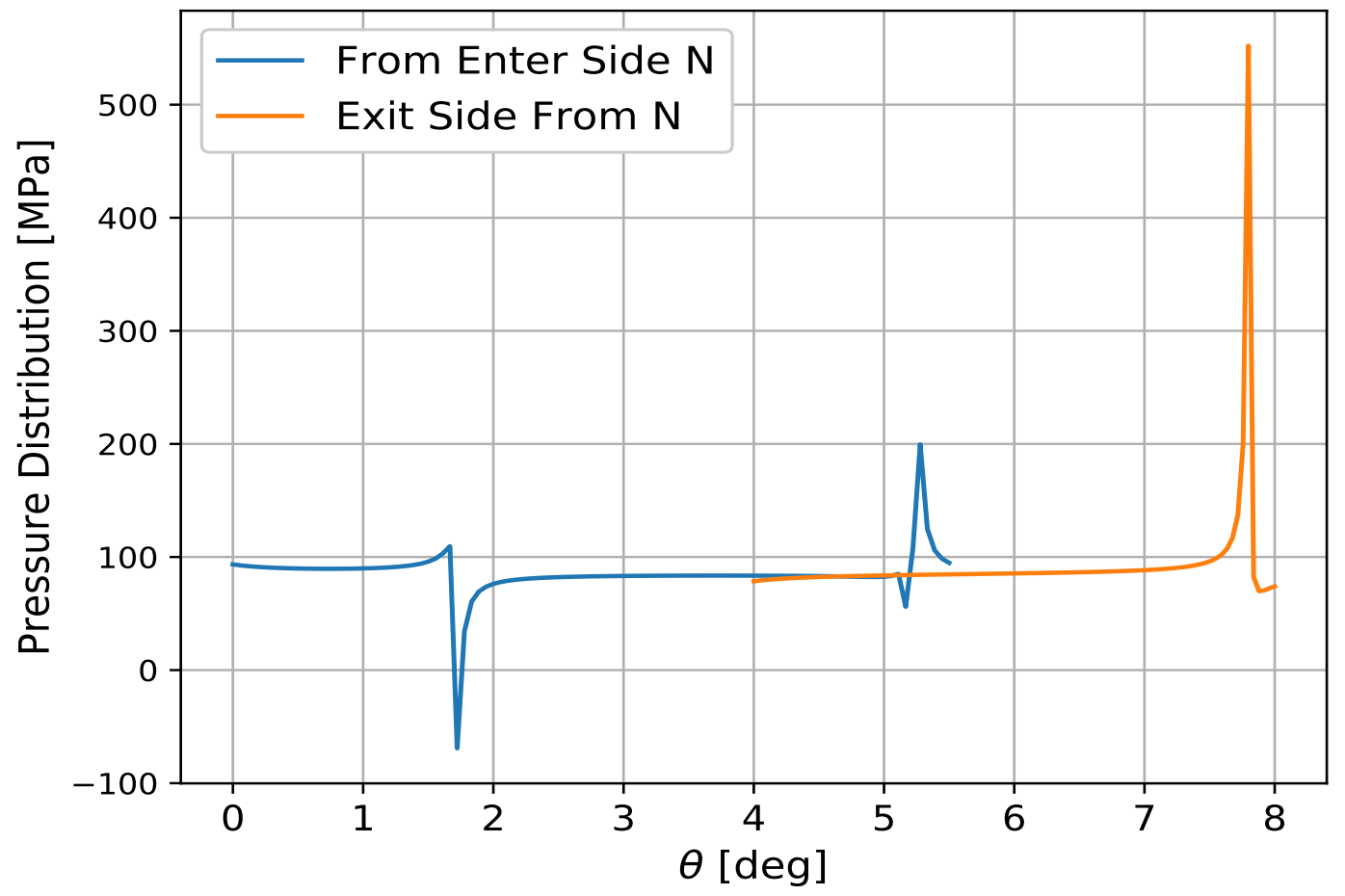

Figure 10. Pressure distribution phenomena under rolling contact from enter Side and the exit side of the neutral point versus the bite angle 


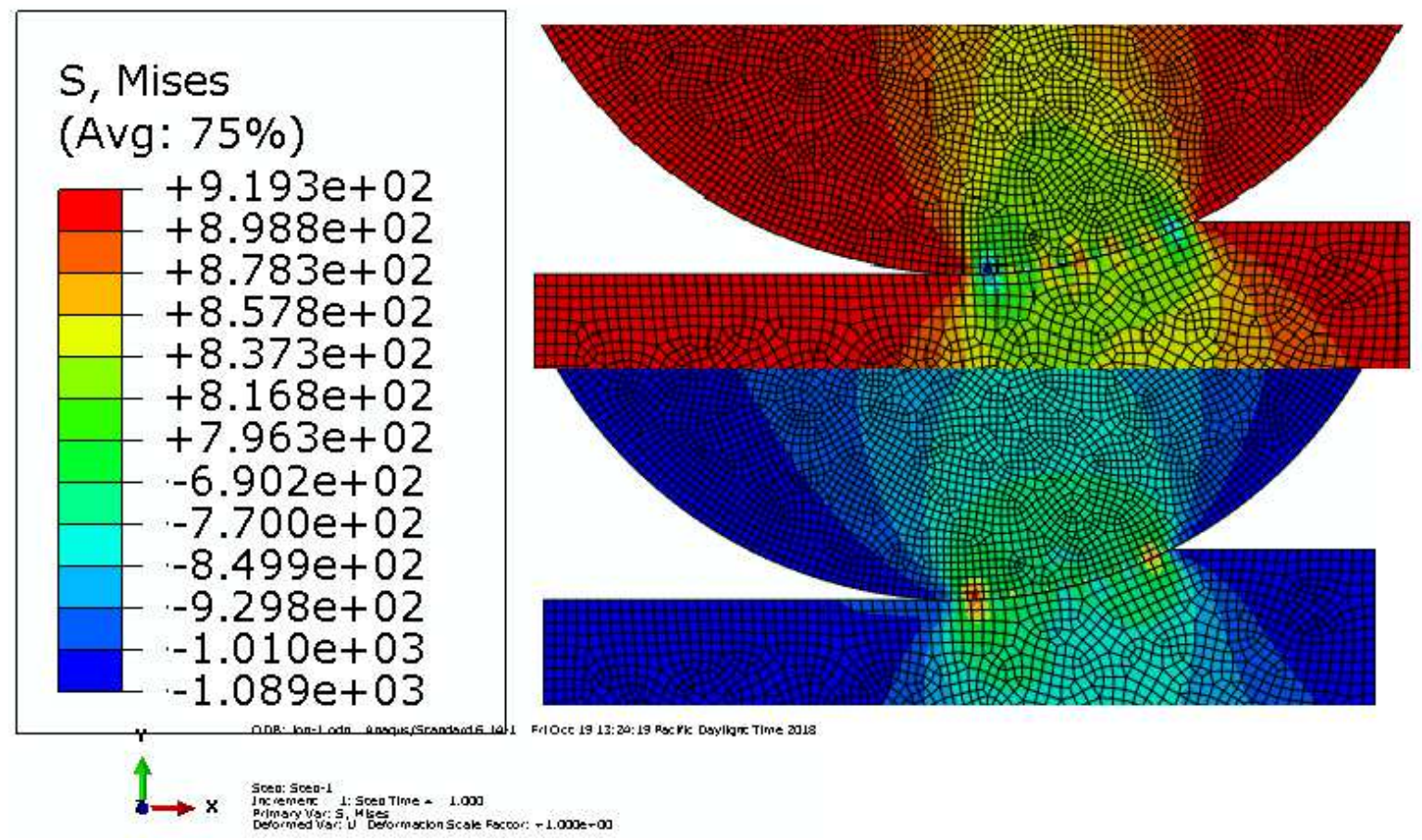

Figure 11. Stress distribution along the arc of contact during plasticity deformation in the global section view

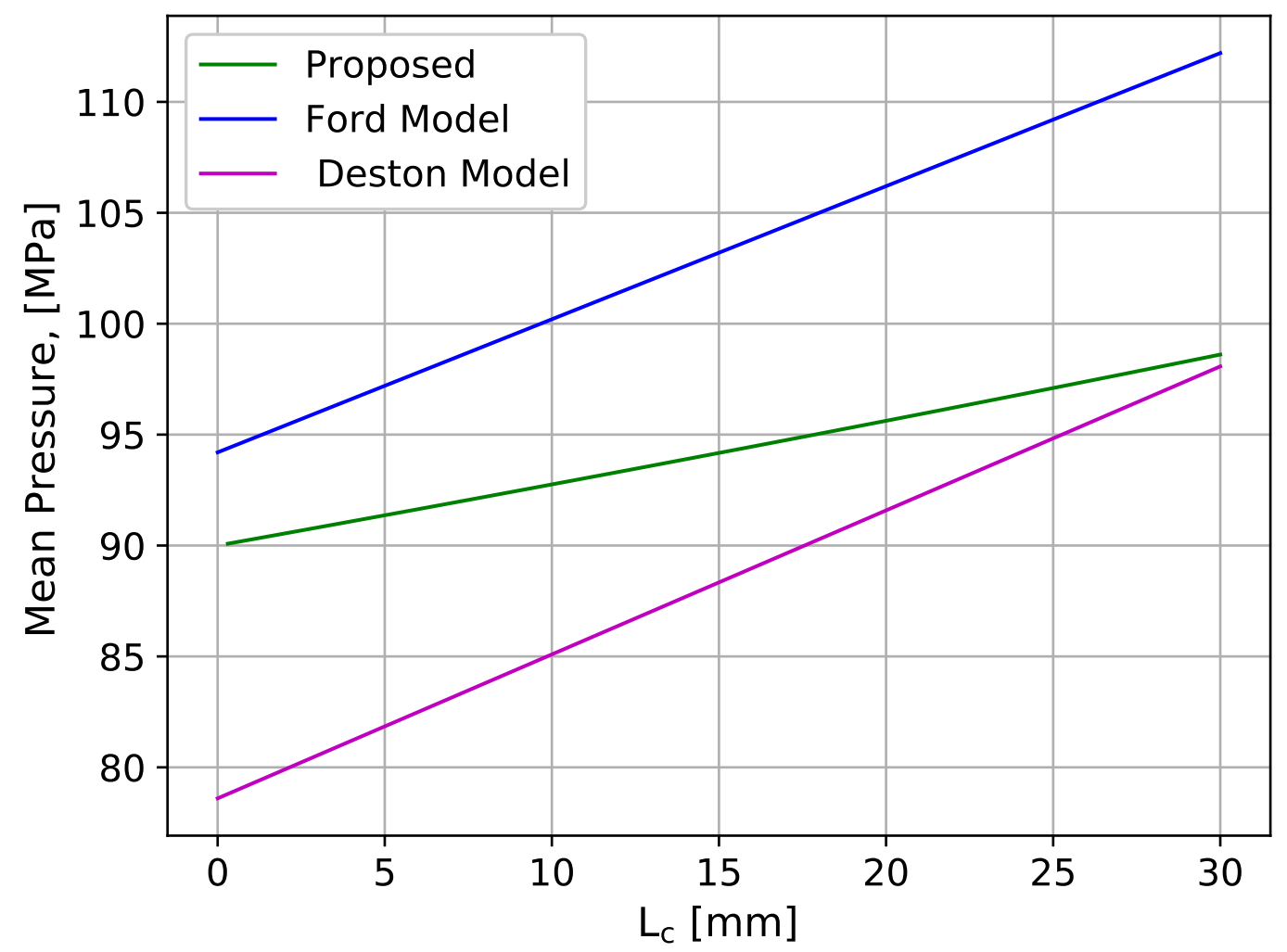

Figure 12. Mean pressure lersus contact length 


\section{The Deformation of the Rolling Die and Constitutive Equation}

The review of Robert [10] concerning the Hitchcock's formula [14] to calculate the radius of the flattened is not accepted, as mentioned above. Rolling die deformation modeling is the core model of this section which can determine stress behavior under rolling contact for number of $\mathrm{N}$. When the numerical modeling is a hotspot research to tackle the experimental tedious tasks and expenses.

The problem of the deformation of the rolling die is treated here by assuming that a solid cylinder, subjected to non-symmetrical loads. The schematic loading diagram of a rolling die is shown in Figure 13. The loading consists of the roll pressure and the interfacial shear stress, where the roll pressure is designated by $P(r)$ and the interface shear stress by $\tau_{r \theta}$. These loads must be balanced by a statically equivalent force system, the location of which would depend on the type of mill considered. For four-high mills or six-high mills the backup rolls would supply the necessary balance, while for two-high mills the reaction forces would be applied through the bearings of the rolling die journals.

As the present analysis is concerned with a two-dimensional treatment of the rolling die of a two-high mill (usually used in continuous casting) and die bending is neglected. The balancing loads are taken to be distributed over the dies with $2 \xi=\pi$, where $2 \xi$ is the extent of the pressure distribution of the now imaginary back-up roll instead of journal bearings. This condition ensures that the mid planes of the dies remain undeformed and stationary.

The stress distribution in any problem of linear elasticity should satisfy the biharmonic equation, which in $2 D$ cylindrical coordinates is

$$
\left(\frac{\partial}{\partial r^{2}}+\frac{1}{r} \frac{\partial}{\partial r}+\frac{1}{r^{2}} \frac{\partial^{2}}{\partial \theta^{2}}\right)\left(\frac{\partial^{2} \varphi}{\partial r^{2}}+\frac{1}{r} \frac{\partial \varphi}{\partial r}+\frac{1}{r^{2}} \frac{\partial^{2} \varphi}{\partial \theta^{2}}\right)=0
$$

where the coefficients of terms singular at the origin were taken to equal zero. The radial and shear stresses are then obtained terms of the Airy stress function

$$
\sigma_{r r}=\frac{1}{r} \frac{\partial \varphi}{\partial r}+\frac{1}{r^{2}} \frac{\partial^{2} \varphi}{\partial \theta^{2}}
$$

and

$$
\tau_{r \theta}=\tau_{\theta}=-\frac{\partial}{\partial r}\left[\frac{1}{r}\left(\frac{\partial \varphi}{\partial \theta}\right)\right]
$$

Following the procedure of [22-25], the stress and strain distributions in the rolling die in a state of plane strain may be calculated from a stress function by using biharmonic functions

$$
\begin{aligned}
\varphi= & c_{0} r^{2}+d_{1} r^{3} \sin \theta+d_{2} r^{3} \cos \theta+\sum_{n=2}^{\infty}\left(a_{1 n} r^{n}+b_{1 n} r^{n+2}\right) \sin (n \theta)+ \\
& \left(a_{2 n} r^{n}+b_{2 n} r^{n+2}\right) \cos (n \theta)
\end{aligned}
$$

where the constants $a_{1 n}, a_{2 n}, b_{1 n}, b_{2 n}, c_{0}, d_{1}$ and $d_{2}$ need to be determined such that the stress boundary conditions at $r=R$ are satisfied. They are determined next by representing the normal and shear loading on the rolling die's surface

$$
\sigma_{r r}=P(r) \quad \text { and } \quad \tau_{r \theta}=\tau(\theta)
$$




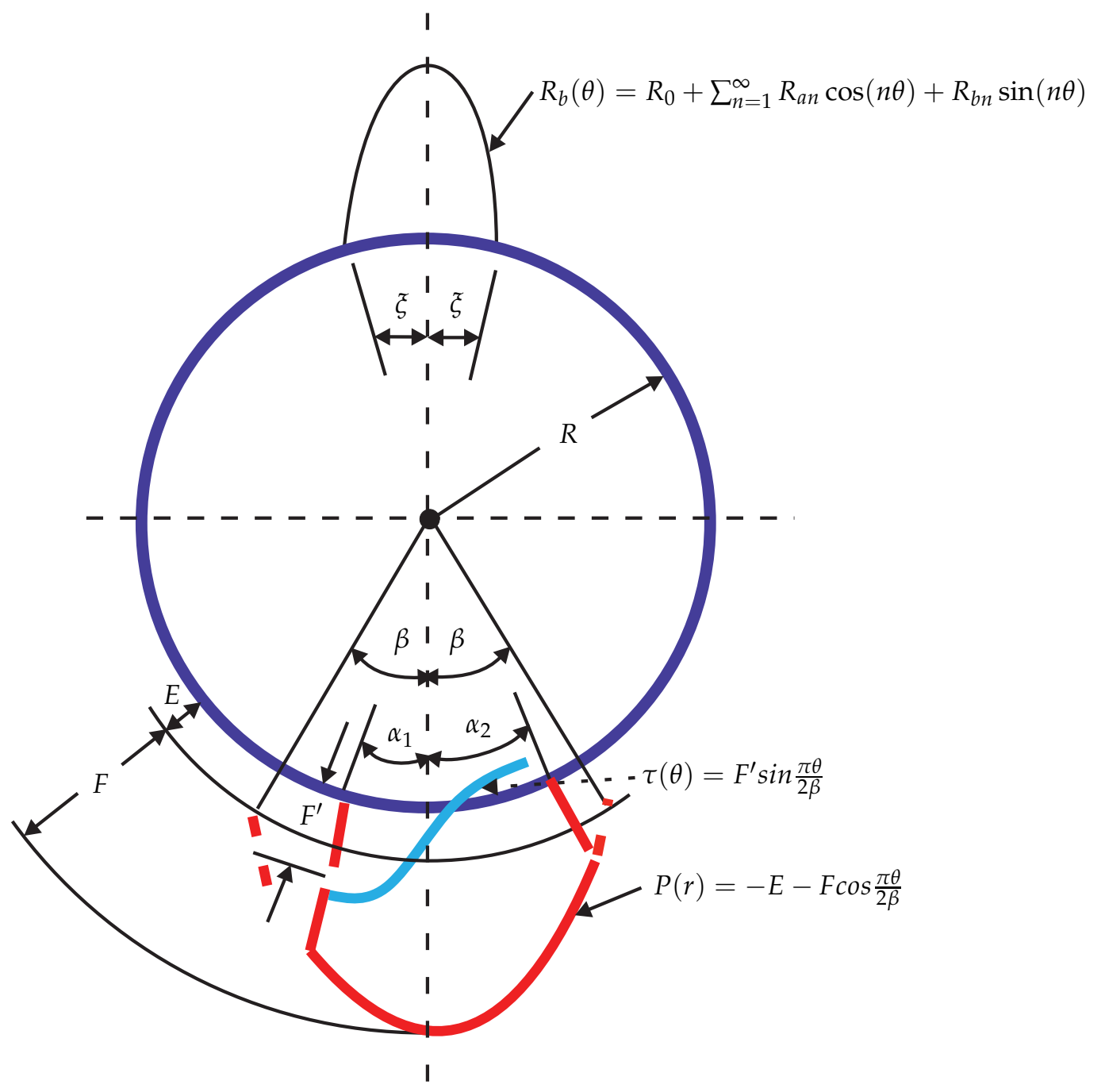

Figure 13. The loading diagram of the rolling die showing the rolling pressure and the interfacial shear stress distributions in addition to the forces that keep the die in equilibrium [23]

Normal and shear loading on the rolling die's surface in terms of fourier series

$$
P(r)=P_{a 0}+\sum_{n=1}^{\infty}\left[P_{a n} \cos (n \theta)+P_{b n} \sin (n \theta)\right]
$$

and

$$
\tau(\theta)=\tau_{\theta}+\tau_{a 0}+\sum_{n=1}^{\infty}\left[\tau_{a n} \cos (n \theta)+\tau_{b n} \sin (n \theta)\right]
$$

where the coefficients are obtained from the Euler formula. For the normal pressure distribution,then

$$
\begin{gathered}
P_{a 0}=\frac{1}{2 \pi} \int_{a_{1}}^{a_{2}} P(\theta) d \theta+\int_{-\pi / 2}^{\pi / 2} R_{b}(\theta) d \theta \\
P_{a n}=\frac{1}{\pi} \int_{a_{1}}^{a_{2}} P(\theta) \cos (n \theta) d \theta+\int_{-\pi / 2}^{\pi / 2} R_{b}(\theta) \cos (n \theta) d \theta
\end{gathered}
$$


and

$$
P_{b n}=\frac{1}{\pi} \int_{a_{1}}^{a_{2}} P(\theta) \sin (n \theta) d \theta+\int_{-\pi / 2}^{\pi / 2} R_{b}(\theta) \sin (n \theta) d \theta
$$

And for the shear stress distribution

$$
\begin{gathered}
\tau_{a o}=\frac{1}{2 \pi} \int_{a_{1}}^{a_{2}} \tau(\theta) d \theta \\
\tau_{a n}=\frac{1}{2 \pi} \int_{a_{1}}^{a_{2}} \tau(\theta) \cos (n \theta) d \theta
\end{gathered}
$$

and

$$
\tau_{a n}=\frac{1}{2 \pi} \int_{a_{1}}^{a_{2}} \tau(\theta) \sin (n \theta) d \theta
$$

The roll pressure distribution in the roll gap can also expressed as a cosine function but it needs the compression with Eq.(43)

$$
P(r)=-E-F \cos \frac{\pi \theta}{2 \beta}
$$

Shown in Figure 13, or alternatively, it may be given as a set of calculated points. In Eq.(59) $E$ and $F$ are constants. The function $R_{b}$ in Eq.(53), (54) and (55) represents the reactions required to keep the rolling die in equilibrium. This can be calculated by expressing the reactions using Fourier series.

$$
R_{b}(\theta)=R_{0}+\sum_{n=1}^{\infty} R_{a n} \cos (n \theta)+R_{b n} \sin (n \theta)
$$

again, where the coefficients are obtained by the Euler formula

$$
\begin{gathered}
R_{0}=-\frac{1}{\pi^{2}} R_{m} \xi \\
R_{a n}=-2 \xi R_{m} \frac{\cos [(-\pi+\psi+\xi) n]+\cos [(-\pi+\psi-\xi) n]}{\pi^{2}-4 \xi^{2} n^{2}} \\
R_{a b n}=-2 \xi R_{m} \frac{\sin [(-\pi+\psi+\xi) n]+\sin [(-\pi+\psi-\xi) n]}{\pi^{2}-4 \xi^{2} n^{2}}
\end{gathered}
$$

In the above equations $\psi$ is the angle between the resultant reaction force and the vertical axis, $R_{m}$ is the amplitude of the reaction force and $\xi$ represents half of the angle over which reaction $R_{b}$ is distributed. It is noted that for beyond to two mill the value of $\xi$ may be determined from the Hertz contact stresses. However, as was mentioned above, for a two high mill the reactions are represented by letting $\xi=\pi / 2$ which in fact indicates the distribution of those forces across a diametral plane of the rolling die. In Eq.(52) the shear stress distribution can be is represented by

$$
\begin{gathered}
\tau(\theta)=F^{\prime} \sin \frac{\pi \theta}{2 \beta} \\
a_{1 n}=\frac{n P_{b n}-(n-2) \tau_{a n}}{2 n(n-1) r_{b}^{n-2}}, \quad a_{2 n}=\frac{n P_{a n}-(n-2) \tau_{b n}}{2 n(n-1) r_{b}^{n-2}} \\
b_{1 n}=\frac{P_{b n}-\tau_{a n}}{2 n(n-1) r_{b}^{n-2}}, \quad b_{2 n}=\frac{P_{b n}-\tau_{a n}}{2 n(n-1) r_{b}^{n}} \\
d_{1}=\frac{P_{b 1}}{2 r_{b}}=-\frac{\tau_{a 1}}{2 r_{b}}, \quad d_{2}=\frac{P a_{1}}{2 r_{b}}=\frac{\tau_{b 1}}{2 r_{b}}
\end{gathered}
$$




$$
c_{0}=\frac{P_{a 0}}{2}
$$

To determine the strain components one can use the plane strain form of hook's law

$$
\varepsilon_{r r}=\frac{1+v}{E_{r}}\left[(1-v) \sigma_{r r}-v \tau_{\theta}\right], \quad \varepsilon_{\theta \theta}=\frac{1+v}{E_{r}}\left[-v \sigma_{r r}+(1-v) \tau_{\theta}\right]
$$

The comparison between the numeric and finite element simulation result with experimental data is presented in Figure 14. Where the initial load 90MPa is considered for both computational analyzing, the result shows good overlapping but experimental data that obtained from the literature shows the difference due to non considering of the initial load over the whole cyclic contact during the experiment made. And also after computer program was written to compute the system of numeric Figure 52 for various values of the input parameters, in meanwhile, including 3D modeling for surface folding due to over loads as shown in Figure 15 and 16, respectively. At the end overall radial and tangential stress for number $\mathrm{n}$, in contact is modeled where the result is shown in Figure 17.

A critical issue of this analysis consists of the accurate selection of all parameters as input for the numerical simulation and finite simulation often difficult under this circumstance. This work simplified approach to compute mechanical stresses in rolling die of hot milling, based on a plane strain, subjected on its surface to mechanical loads for number of cyclic loads. Presented approach is obviously a preliminary investigation, whose contribution is more methodological than quantitative. The these model can be used as a tool in the most challenging aspect of hot activities, concerning the identification of the elasticity damage mechanisms in rolling die. Actually, this approach looks quite promising, since it avoids analyzing the slab behavior in rolling gap, is able to catch relevant phenomena induced by rolling contact and identifies the radial and tangential stress behavior of the rolling die material.

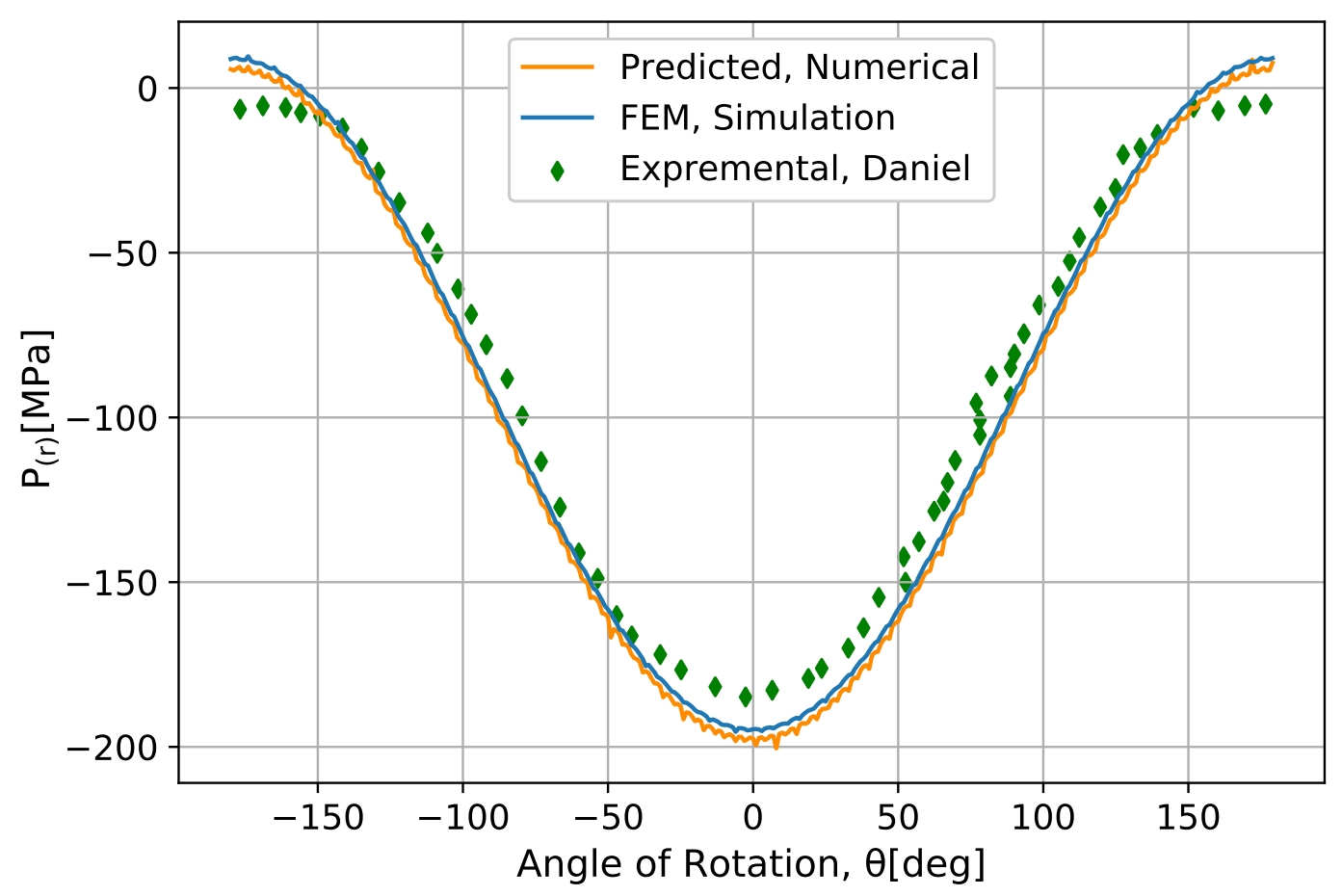

Figure 14. Radial stress distribution $\left(\sigma_{r r}^{M e}\right)$ in rolling die under rolling gap [Data Source; 26] 


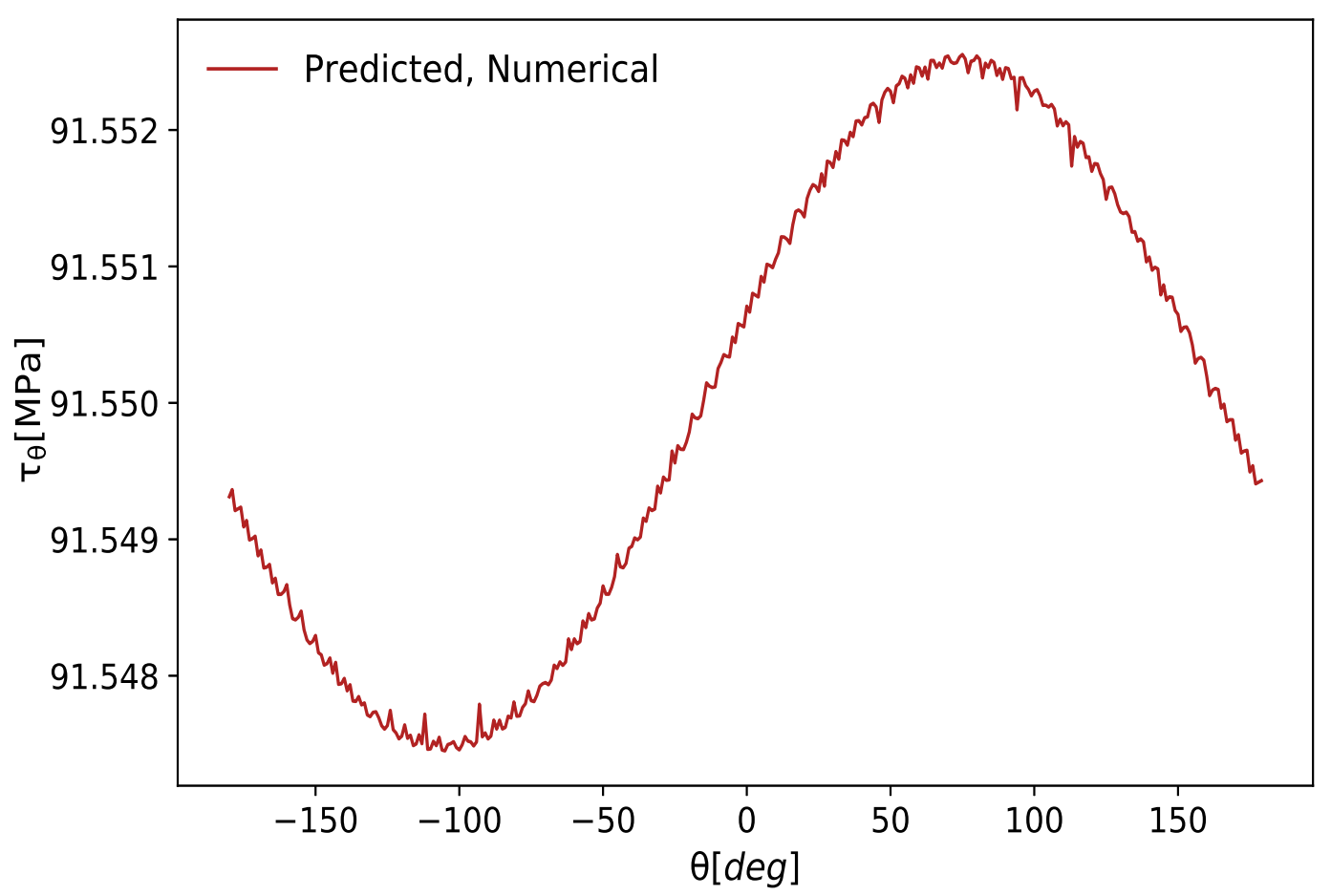

Figure 15. Circumferential stress distribution, $\tau_{\theta}^{M e}$ under rolling gap

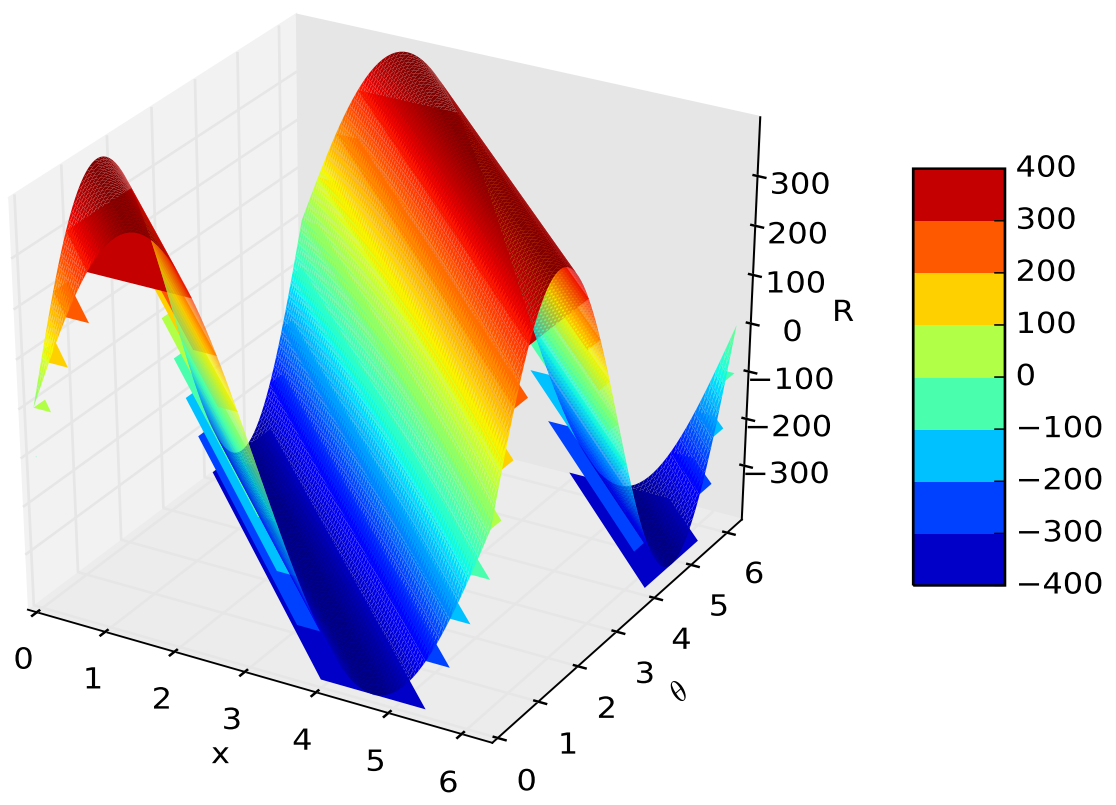

Figure 16. 3D surface folded under rolling contact due to compressive and tension loads 


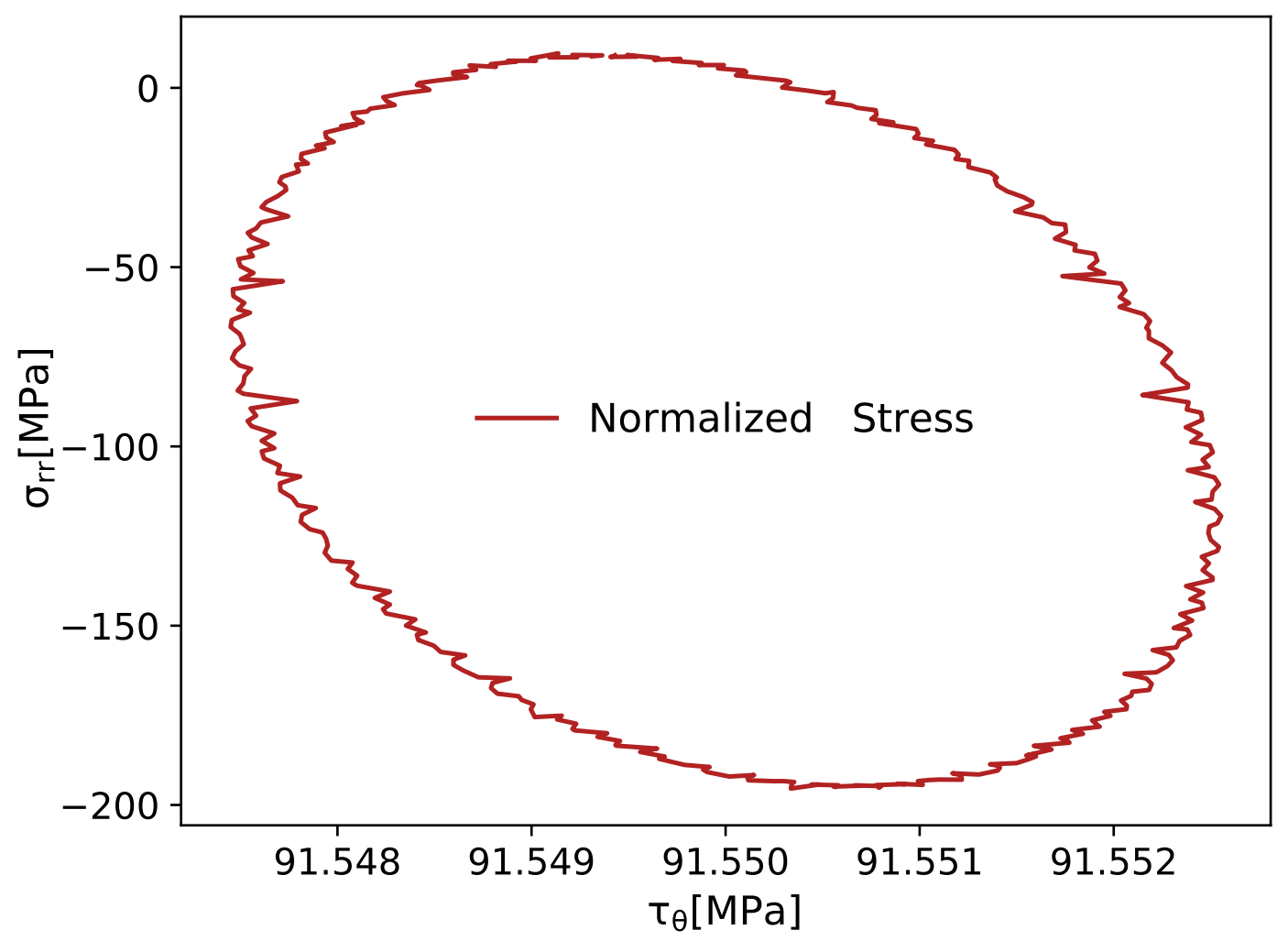

Figure 17. Normalized stress on the rolling die surface under rolling gap

\section{Conclusions and outlook}

The results from the numerical calculations are carried out based on geometric relationship for rolling contact gap, normal contact and tangential stress distribution, neutral point, coefficient friction without including front and back tensions . In short, the work of this paper demonstrate that nature of rolling die/slab contact function into pressure distribution under rolling gap with help of schematic representation. In the same way, new models are proposed with the simplified versions for hot rolling load condition where approximation values of loading phenomena sufficiently predicted. Especially, elasticity deformation of rolling die in terms of radial and tangential stress are modeled for any number of cyclic loads in which values are agreed with experimental data in literature and FEM simulation within acceptable ranges. For further investigation, thermomechanical stress and fatigue life prediction may recommendable taking into account the result of this paper.

\section{References}

1. Schey, A. Tribology in metalwork: friction, lubrication and wear; ASM, Metal Park, Ohio, 1983;. ISBN-13: 978-0871701558.

2. Lenard, G. Primer on flat rolling; ELSEVIER: British, 2014;. pp. 39-55, ISBN.

3. Bay, N.; Waneim, T. Real area of contact and friction stress at high pressure sliding contact; ELSEVIER: Netherlands, 1976; pp. 201-209, ISBN.

4. Chenot, J. Finite element calculation of unilateral contact with friction in nonsteady-state processes; In: Proceedings of the NUMETA Conf. Swansea, UK, 1987. pp. 1341-1354 ISBN.

5. Kalker, J. Three dimensional elastic bodies in rolling contact; Kluwer Academic: Dordrecht, 1990;. ISBN 978-94-015-7889-9.

6. Fourment, L.; Mocellin, K.; Chenot, J. An implicity contact algorithm for the 3D simulation; Pineridge Press, Swansea, 1997; pp 156-165, ISBN. 
7. Johnson, K. Adhesion and friction between a smooth elastic spherical asperity and a alane surface; Royal Soc.: Great Britain, 1997; pp. 163-179, ISBN.

8. Nam-Ho, K. Introduction to nonlinear finite element analysis; Springer: New York, 2015; ISBN 978-1-4419-1746-1.

9. Bowden, F.; Tabor, D. Friction and lubrication of solids; Oxford University Press, 1950, ISBN: 9780198507772.

10. Roberts, W. Cold Rolling of Steel; Manufacturing Engineering and Materials processing, CRC Press: New York, 1979; ISBN 9780824767808.

11. Avitzur, B. Metal forming: processes and analysis; McGraw-Hill: New York, 1987; ISBN-13: 978-0070025103.

12. Avitzur, B. Friction aided strip rolling with unlimited reduction; In. J. of Mach.: Great Britain, 1980; pp. 197-210, ISBN.

13. Rudolf, P.; Tibor, K. New numerical solution of von karman equation of lengthwise rolling; Hindawi Publ. Corp., 2015. doi: $10.1155 / 2015 / 843720$.

14. Hitchcock, J. Elastic deformation of rolls during cold rolling; ASME Report of SRC on Roll Neck Bearing, 1935; pp. 33-41, ISBN.

15. Dian-Hua, Z.; Yuan-Ming, L.; Jie, S.; De-Wen, Z. A novel analytical approach to predict rolling force in hot strip finish rolling based on cosine velocity field and equal area criterion; In. J. Adv. Manu. Techn., 2016; pp. 843-850, ISBN.

16. Nascimento, H.; Shigak, Y. A study of the rolling load calculation models for flat cold rolling process; J. Comp. Meth. Eng.: Brazil, 2016; ISSN: 2447-6102.

17. Rodney, H. Relations between roll-force, torque, and the applied tensions in strip-rolling; Irn. Ste. Res. Ass., 1950; https://doi.org/10.1243/PIME_PROC_1950_163_017_02.

18. Li, Y.; Sellars, C. Development of forward slip friction measurement method of rolling; IMMPETUS, 1998.

19. Lenard, J.; Barbulovic-Nad, L. The coefficient of friction during hot rolling of low carbon steel strips; J. of Tribology Trans., 2002; pp. 840-845. doi:10.1115/1.1454106.

20. Ford, H.; Alexander, J. Simplified hot-rolling calculations; J. Inst. Met., 1963; pp. 397-404, ISBN.

21. Denton, B.; F., C. Roll load and torque in the hot rolling of strip; J. Iron Steel Inst., 1972; pp. 606-616, ISBN.

22. Michell, J, H. Some elementary distribution of stress in three dimensions; Proc. Lond. Math. Soc., 1900; https://doi/pdf/10.1112/plms/s1-32.1.23.

23. Roychoudhuri, A.; Lenard, J. A mathematical model of cold rolling-experimental substantiation; Proc. 1st Int. Conf. Techn. Plast: Tokyo, 1984, pp. 1138-1143, ISBN.

24. Pietrzyk, M.; Lenard, J. Thermal-mechanical modelling of the flat rolling process; Mat. Res. Eng.: Heidelberg, 1991; ISBN 978-3-642-84325-9.

25. Hartley, P.; Pillinger, I.; Sturgess, C. Numerical modelling of material deformation processes; Springer: London, 1992, ISBN 978-1-4471-1745-2.

26. Daniel, W. Experimental evaluation of contact stress during cold rolling process with optical fiber bragg gratings sensors measurements and fast inverse methodes; J. Mat. Proc. Techn., 2015; pp. 105-123, ISBN. 